\title{
Inthalt.
}

Borbemertung. . . . . . . . . S IJI-V

I. Cinfahrungsgefes . . . . . . . $1-8 \quad 1-4$

I. Strafgefegbuh.

Einleitende Bejtimuungen . . . . . . $1-12$ j-8

\section{Grfter Teil.}

Bon Der Beftrafung Der Berbredjen, Bergeben und Uebertretungen im $\mathscr{A}$ Mgemeinen.

Erfter פbidnitt. Strafen . . . . . . 13-42 9-19

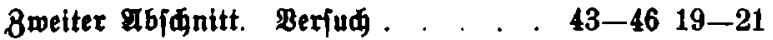

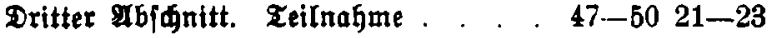

Bierter פbj内nitt. Brände, welde bie

Strafe ausfめliépen ober milbern . 51-72 23-32

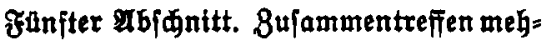

rerex ftrafbarer Ganblungen . . . 73-79 32-35

\section{3weiter Teil.}

Bon den einzelnen Berbreden, Bergeben und

uebertretungen unb beren Beftrafung.

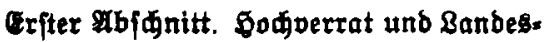

perrat.

$80-9335-42$ 


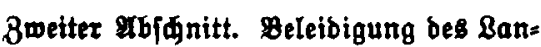
beskerrn . . . . . . . . . . 94-97 43-45

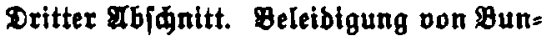
besfüriten . . . . . . . . . . 98-101 45-46

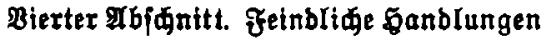
gegen befreunbete Staaten. . . . . 102-104 46-47

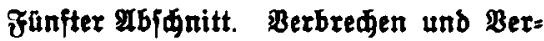
geben in Pegiebung auf bie Pus: Afbung ftaatsbürgerlider Mtedite . . 105-109 48-49

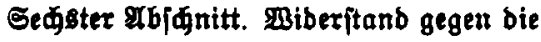
Staatsgemalt . . . . . . . . . 110-122 $49-54$

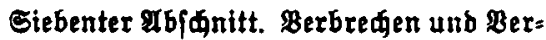

gehen miber bie ôfientlife Drbnung 123-145a 54-64

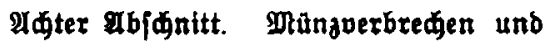
Manjoergeben . . . . . . . . . . 146-152 64-66 Neunter פ⿹丁口nitt. Mleineid . . . . . 153-163 66-71

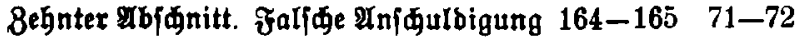
Elfter Ibjunitt. Bergehen, melde fí auf bie Meligion beziehen . . . . . 166-168 72-73

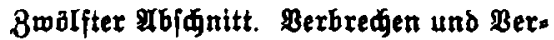
geben in Pejiebung auf ben \$er: poneritand $169-170 \quad 73$

Dreigebnter 2rbłanitt. Berbreden unb

Bergehen wiber bie Sittlidgleit . . 171-184b $74-81$

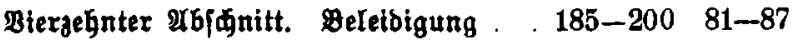

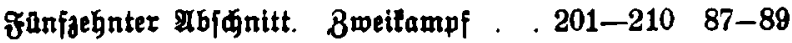

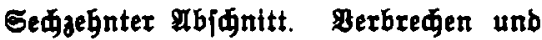
Bexgeben wiber bas Reben . . . 211-222 89-93 


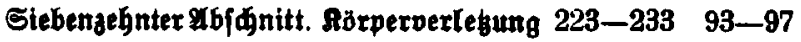

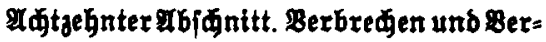
gehen wiber bie perfänlide హreibeit 234-241 97-100

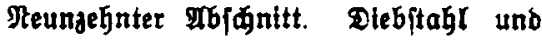
unteriblagung . . . . . . . . . . 242-248 100-105

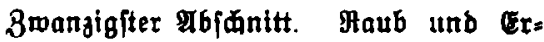
prefung . . . . . . . . . . . . . 249-256 105-108

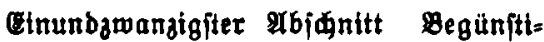
gung unb geblerei . . . . . . 257-262 108-111

8weiunbjwanaigfter Abjunitt. Betrug unb untreuse . . . . . . . . 263-266 111-114

Dreiundzmanaigfter Áfidnitt. Urtunben=

fälfø̆ . . . . . . . . . . . 267-280 114-119

Bterunbawanatgfter $\mathfrak{A b}$ f

(aufgeboben) . . . . . RD. \$\$ 239-244 119-123

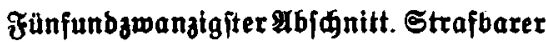
Eigennub und Berlegung frember Bebeimnifie . $284-302 \mathrm{e} 123-132$

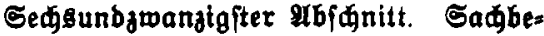
idabigung $303-305 \quad 133-134$

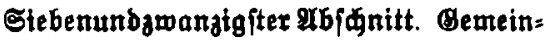
gefăgrli山e Berbreden unb Bergeben 306-330 134-146

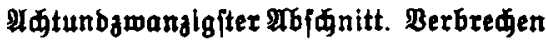
und Bergefen im IImte . . . . . 331-359 147-157

Neununbamanaigiter gbidnitt. Uebertre: tungen. . . . . . . . . . . 360-370 157-173 


\section{Ethang:}

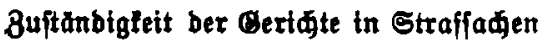

$174 \pi$.

Sa मregifter

182 ff.

\section{Derzeidnis}

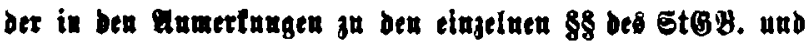
te Gin|Ge|. absedrudten ftrafredtliden Nebengeleke:

1. Einführg̊gef. f. Elfaß̧=\&othringen vom Sctte

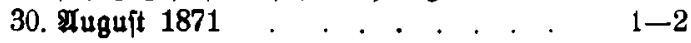

2. Spionagegef. v. 3. Эuli 1893 . . . . $\quad 39-41$

3. Bef., betr. Die Beftruig. ber Mtajejtüts= beleibigg., v. 17. F̧ebruar 1908 . . . 43

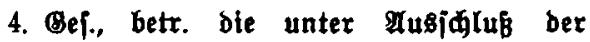
Deffentlidfeit ftattīndenben Beridts= verhandlungen, v. 5. April 1888 . . . 81

o. Bef. geg. ben unlaut. \$ettbemerb $\mathfrak{v}$. 7. Juni 1909, $\S \S 15,17 \uparrow ., 20$. . . . $83,12 \div-180$

6. Bej., betr. bie Beptrafg. ber Entgiegg. eleltr. Mrbeit, v. 9. April 1900 . . . 101

7. Depotgef. v. 5. Julf 1896, §§ 9-12 . . 104, 120

8. Dorjengef. v. 27. Mtai 1908, §§ $88 f$., $94 \mathrm{f}$. . . . . . . . . . . . . $111-112$

9. Aonlurborbnung, $\$ \S 239-244$. . . . 118-123

10. Bef. Iber b. Sifierg. b. Bauforbergn.

v. 1. Juni 1909 , \&8 5 f. . . . . . . 120-121 